\title{
The sustainable promotion strategy of transfer hub in megapolis
}

\author{
Marianna Ababkova ${ }^{1, *}$ and Olga Vasileva $^{1}$ \\ ${ }^{1}$ Peter the Great Saint-Petersburg Politechnical Univesity, 29, Polytechnicheskaya, 195251, \\ St.Petersburg, Russia
}

\begin{abstract}
This article presents a methodological approach to the development of promotion strategy for a transport hub in a metropolis. In response to the modern megapolises' growth, transport hubs perform the role of multi-functional public facility, implementing a wide set of not only transport and logistics services, but also a combination of social, shopping and entertainment functions to passengers, both tourists and local residents. The material deals with the concept of transfer hub as a transport and communication space - a territory of human existence and activities, so the issues of integration of promotion tools and marketing strategy implementation are vital on every stage of transfer hub's existence. The adaptation of the Rodrigue-Notteboom model is proposed with the embedded marketing tools and activities to ensure transfer hub's functioning as a transport and communication space. The stages of marketing promotion strategy implementation include marketing research of region's economic and geographical position, traffic development and management, consumer satisfaction, promotion and marketing support of transfer hub's services and commercial facilities among the population and tourists. The implementation of transfer hub project based on the effective marketing strategy to change certain social and cultural environment and the traffic psychology of the population of the metropolis area.
\end{abstract}

\section{Introduction}

One of the effective approaches to deal with traffic jams in metropolises is transfer hubs' establishment to ensure travelling time reduction and to provide convenience of transfers for the tourists and residents [1].

Transfer hub's development results in the improvement of conditions for the intracity and suburban-urban population commuting. The framework of transfer hub's facilitates the travel schedules combinations of various transport modes, as from ensuring the interaction of transport in transfer hub, unloading the city's roads, diversification of routes, shift from private transport to public transportation, and continuing with receiving additional income due to additional services and facilities in the transfer hub area [2]. It allows passengers to use the waiting time to make necessary purchases in a comfortable environment, as a result, it can also reduce the flow of cars to the megapolis' shopping centers. Some authors conclude,

\footnotetext{
*Corresponding author: ababkova_myu@spbstu.ru
} 
that the modern transfer hubs perform the role of the full-fledged multi-functional logistics structure that perform a wide range of not only transport, storage, but also consulting, customs, distribution, expeditionary, shopping and other consumer-oriented services [3].

In the table 1 some data on the characteristics of several Russian cities is presented, describing the modern situation with transfer hubs.

Table 1. Some Russian cities' characteristics where transfer hubs to be developed or reconstructed [4].

\begin{tabular}{|c|c|c|c|c|c|c|}
\hline № & City & $\begin{array}{c}\text { City } \\
\text { territory. } \\
\left(\mathbf{k m}^{2}\right)\end{array}$ & City population & $\begin{array}{c}\text { Number of } \\
\text { railway } \\
\text { stations }\end{array}$ & $\begin{array}{c}\text { Number of bus } \\
\text { terminals }\end{array}$ & $\begin{array}{c}\text { Number of } \\
\text { airports }\end{array}$ \\
\hline 1 & Moscow & 2561.5 & 12380664 & 9 & 10 & 4 \\
\hline 2 & $\begin{array}{c}\text { Saint- } \\
\text { Petersburg }\end{array}$ & 1439 & 5281567 & 5 & 8 & 1 \\
\hline 3 & Novosibirsk & 505.6 & 1602915 & 1 & 4 & 1 \\
\hline 4 & Samara & 465 & 1169719 & 1 & 4 & 1 \\
\hline 5 & Kazan & 425 & 1231878 & 1 & 5 & 1 \\
\hline 6 & $\begin{array}{c}\text { Rostov-na- } \\
\text { Donu }\end{array}$ & 348.5 & 1119875 & 1 & 3 & 1 \\
\hline 7 & Irkutsk & 277 & 623424 & 1 & 1 & 1 \\
\hline
\end{tabular}

Design and development of transfer hub, as the authors conclude [4], should be appropriate and cost-effective on the basis of its construction cost and the expected passenger traffic efficiency. Unreasonably and disproportionately large number of transfer hubs will lead to substantial investments, while the insufficient availability will result in irrelevant and redundant traffic congestion, extension of the time spent for transfers, and traffic capability. The area of the city subjected to transport services, transfer hub's zone of influence, and the estimated number of passengers should be taken into account. The table below presents the approximate number of transfer hub in Russian cities (table 2).

Table 2. Assessment of the approximate number of transfer hubs in Russian cities [4].

\begin{tabular}{|c|c|c|c|c|}
\hline № & City & $\begin{array}{c}\text { Number of transfer hub } \\
\text { on the base of railway } \\
\text { stations }\end{array}$ & $\begin{array}{c}\text { Number of other } \\
\text { transfer hubs }\end{array}$ & $\begin{array}{c}\text { Total number of } \\
\text { transfer hubs }\end{array}$ \\
\hline 1 & Moscow & 19 & 231 & 250 \\
\hline 2 & Saint-Petersburg & 13 & 134 & 147 \\
\hline 3 & Novosibirsk & 5 & 74 & 79 \\
\hline 4 & Samara & 5 & 56 & 61 \\
\hline 5 & Kazan & 6 & 62 & 68 \\
\hline 6 & Rostov-na-Donu & 4 & 65 & 69 \\
\hline 7 & Irkutsk & 2 & 40 & 42 \\
\hline
\end{tabular}

The construction and maintenance of the modern transfer hub are expensive, complex multidimensional tasks not to be considered unilaterally. Challenging areas in the large cities therefore need to be explored to gain a deeper understanding of its economic and geographical position, traffic development and management, integration with the locality before such projects can be implemented [5]. For this purpose, large-scale studies of passenger flows should be carried out, and the decision to build a transfer hub should be based on the results of such studies [6;7]. Travel comfort is a factor that will increase a number of public transport users. A multi-level solution of transport and transfer hubs will save city's territory.

But focusing on transfer hub's nature only as territorial entity at the nodal point of the city's transport system significantly reduces the range of parameters important for its 
functioning. The essence of transfer hub includes not only infrastructure base, operational work, transport and cargo processing technologies, multi-level logistics services, but also the virtual (information processing) and marketing activities and consumer support within the implementation of transfer hub's strategy [8].

\section{Methods}

The methodological framework for the development of transfer hub promotion strategy concept included Russian and foreign sources and methods of synergistic, cluster and system analysis.

The implementation of transfer hub's marketing plan provides the basis for its promotion [9] and enables to provide the city population and visitors with information on the functioning of transfer hubs, to maintain and strengthen the loyalty of the users, to increase the number of passengers and the usage of public transport.

In accordance with current practice there are three approaches to the models of transfer hubs. The minimalist model of transfer hub implies a design of a place with different types of transport converge and passenger traffic. Within this philosophy the infrastructure for passenger services (ticket offices, information services, toilets, small recreation halls and shopping pavilions) is to be provided. This approach takes minimum of marketing support and promotion activities to further hub's and its services' usage. The second approach (the complex model) considers transfer hub as a land plot and property complex, where not only transport infrastructure objects are located, but also facilities for safe and comfortable passenger services. The non-core component is expanded by creating additional commercial or public catering establishments and communications (medical and public order facilities). This model requires a range of marketing and promotion tools, from commercials to PR. The broadest and largest model (public facility model) suggests to consider transfer hub as a node of transport and transfer facilities that combine social, service, shopping and entertainment functions to provide a variety of services to passengers and local residents [10]. This model necessitates a wide and substantial set of marketing and communication activities to promote hub not only among the residents, but also among tourists. For example, the Shinjuku hub was opened in Tokyo, connecting the center of Japanese capital with 300 cities in 39 prefectures of the country, in particular, with Kyoto, Nagoya and Osaka. The new transfer hub connects 19 separate small bus stations, the country's largest railway station (3.64 million passengers a day) and two subway stations. Combined ticket offices allow to purchase tickets for routes of 118 carriers. The hub also includes a hotel, currency exchange, and commercial facilities on four floors of the bus station. The total passenger traffic of the hub for the first year of operation amounted to 4 billion passengers [10].

\section{Results}

The construction and operation of a transfer hub must be accompanied by a set of marketing activities to make the project efficient, socially relevant and demand-driven. The new concept of transfer hub could be referred as transport and communication space - a territory of human existence and activities, the form and functions of which is determined by a stable set of movements and interaction of people (fig. 1). 


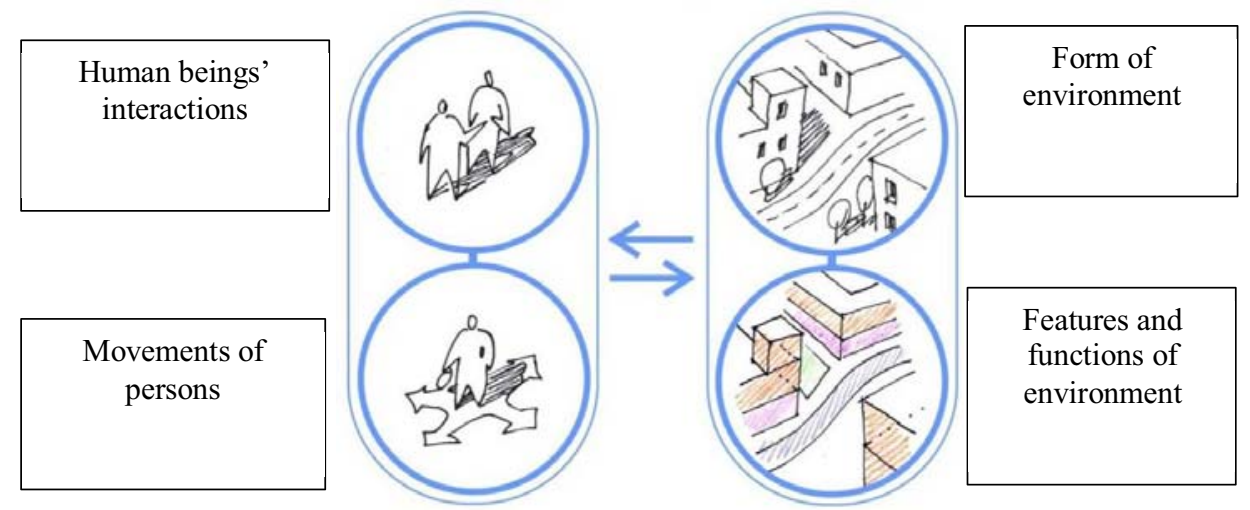

Fig. 1. Transport and communication space [10].

Establishing and maintaining a flexible marketing plan will serve as the basis for a strategy to promote a transfer hub. The strategy for the promotion of a transfer hub should include:

\subsection{A range of measures to promote the transfer hub (finding and employing motivating drivers and citizens to use transfer hub services)}

Such activities could include advertising of the new transfer hub (outdoor, television, print, Internet advertising). Traffic issues in large cities are the subject of preventive information campaigns within the framework of public advertising including items as follows:

- promotion of traffic rules and regulations;

- issues of environmental pollution;

- challenges of traffic management and road safety (traffic jams, parking etc.).

The examples of outdoor public advertising dedicated to traffic regulation and jams are shown on fig. 2 .
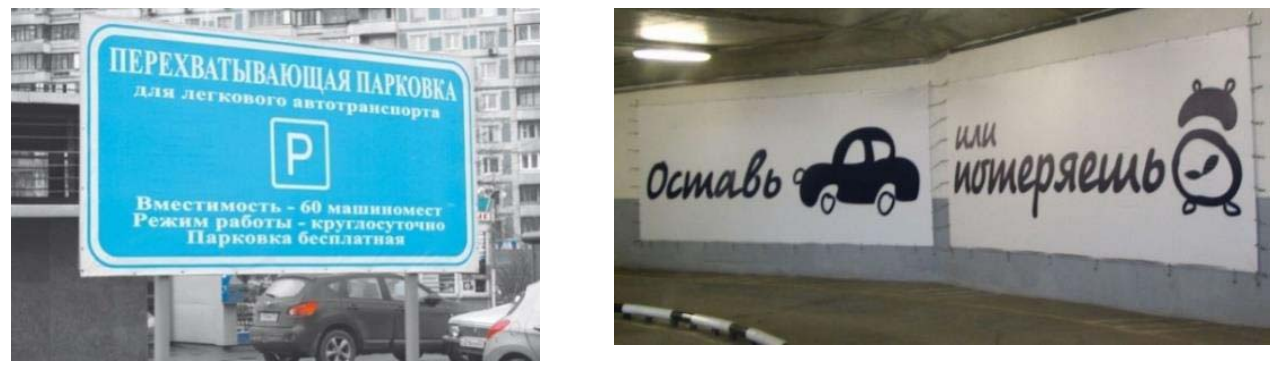

Fig. 2. Outdoor advertising to address traffic regulation problems [11].

Such an advertising campaign should include development of public transport and its promotion, as well as discouragement of private transport usage within the city area in accordance with traffic psychology.

Traffic and transportation psychology $[12 ; 13 ; 14]$ is a field of applied socialpsychological research to provide relevant solutions on the basis of the transport behavior studies to enable congruent transport infrastructure and environment.

The analysis of modern foreign psychological research in this area will bridge the gap in understanding and help to fulfill an adequate assessment of the real situation in a particular metropolis and will add up to forming of marketing promotion of a transfer hub. The 
contribution of traffic and transportation psychology research will help to find out the interaction of actors in urban traffic; ethno-cultural features; the issues of "road maps" (state of transport infrastructure, the choice of route and means of transportation in the city area, information and advertising support of parking lots for various purposes, etc.); improvement of the urban traffic control efficiency; assessment and comparison of unavoidable social risks and social bonuses within a transfer hub development.

Traffic and transportation psychology, in addition to studies of the impact of the road signs' design and location, the optimum functioning of traffic lights, etc., help to determine outdoor and transport advertising colors, drivers' awareness of the availability of parking facilities and how different social groups in the population view public transport. The application of traffic and transportation psychology to design of transfer hub promotion strategy allows to choose the technique of encouragement to motivate potential transfer hub's users.

\subsection{Promotion support for a transfer hub.}

Often passengers refuse to use transfer hubs services for they perceive them as too complicated to use. Thus, a web-based geographic information system, mobile applications, print advertising to explain and facilitate the convenient use of transfer hub are needed. For example, transfer hubs' sites with detailed information on their operation are being created in different countries (fig. 3).

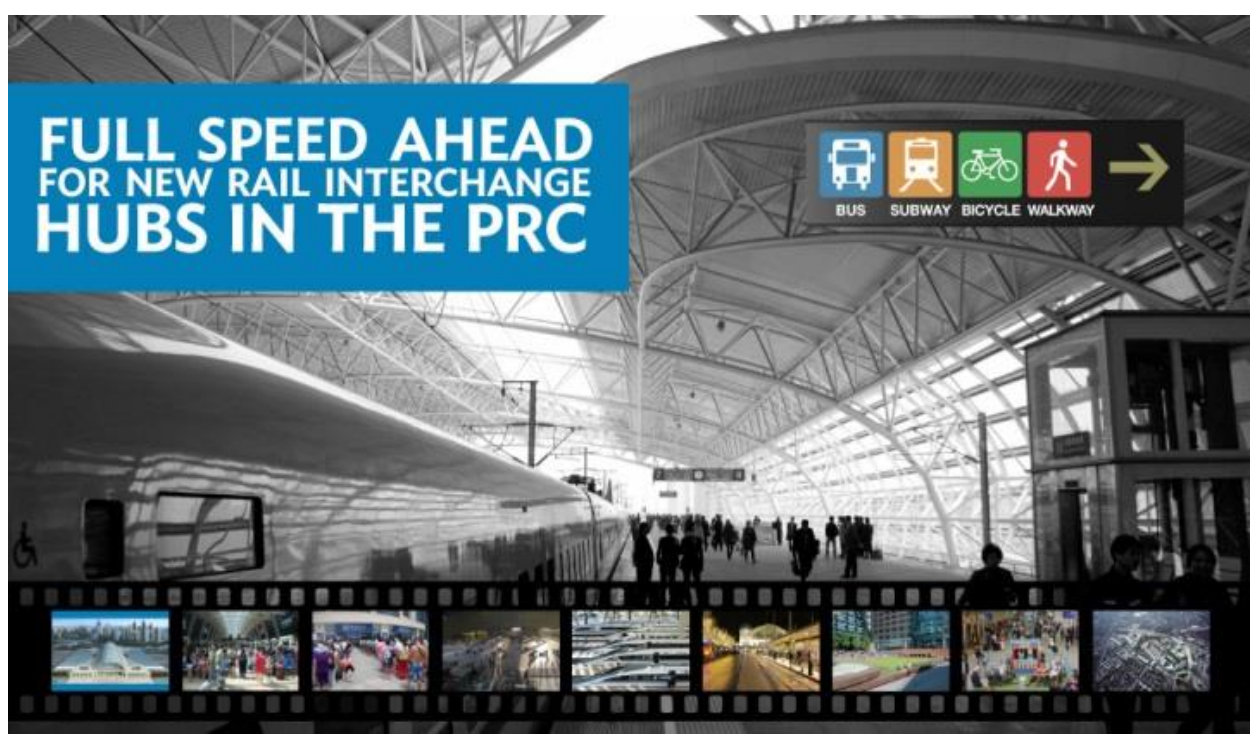

Fig. 3. Chinese transfer hub's website screenshot [11].

It is advisable to create outdoor advertising, signs and signages, and transit advertising on the main highways of the city. As an example of a practical aspect related to the promotion of information support for the transfer hub it can be pointed that Amsterdam has released an information brochure on transfer hubs, and for the convenience of tourists visiting the city, it can be downloaded from the city's tourist site. It contains a detailed description of the location and the use of the Dutch capital's intercepting parking (fig. 5). 


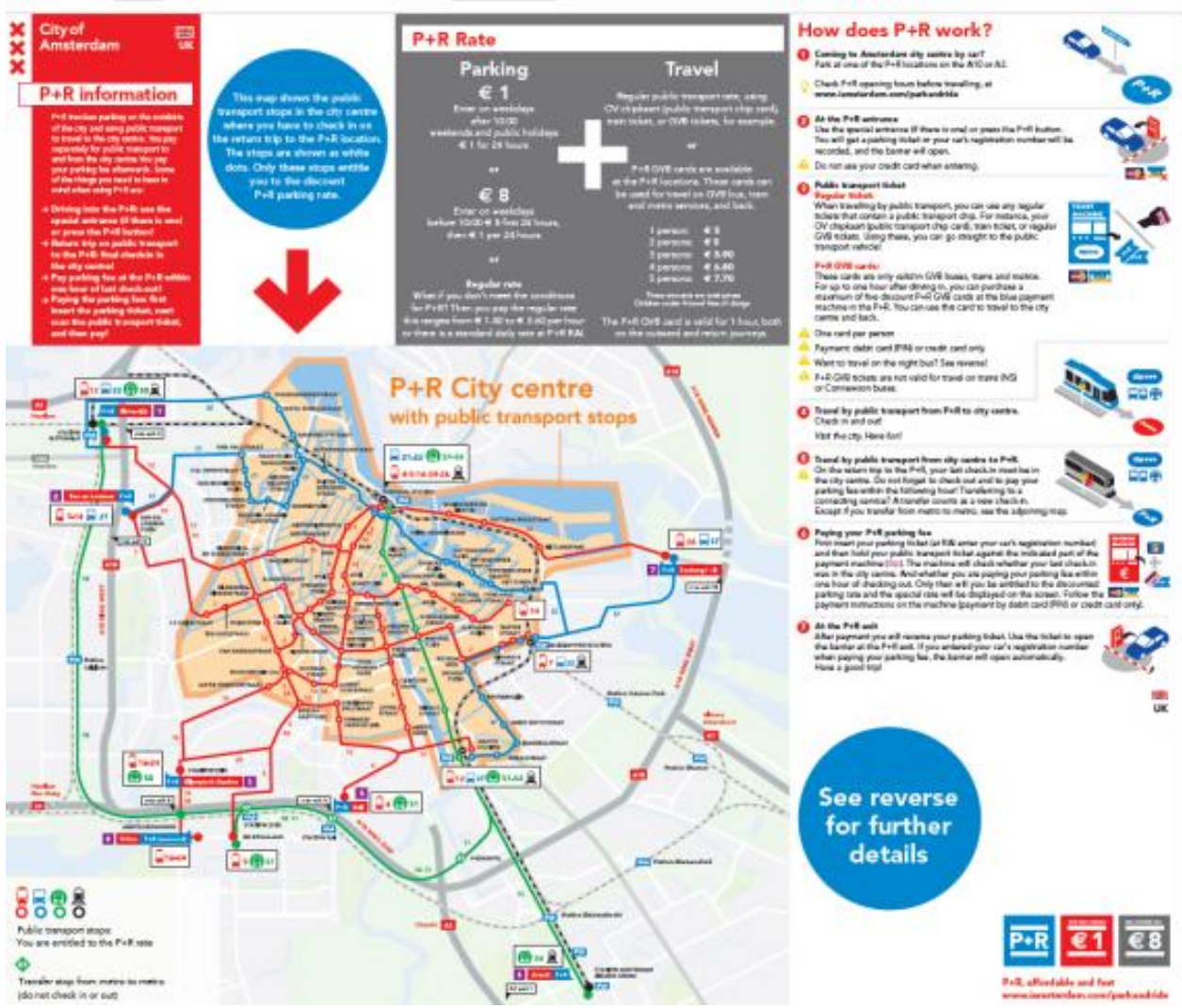

Fig. 4. The example of promotion of intercepting parking in Amsterdam (print advertising) [2].

The main marketing activities for the promotion of transfer hubs services are as follows:

- development and implementation of transfer hubs' service programs;

- real-time information on the functioning of the transfer hubs by the means of digital signage;

-IVR (Interactive Voice Response) -interactive services with a voice menu to allow a caller to communicate with an autoinformator, to address all the substantive issues of concern, to make an order, learn about discounts, events, etc.;

-print ads for transit routes and timetables. An example of effective advertising developed in the United Kingdom is shown in fig. 5. 


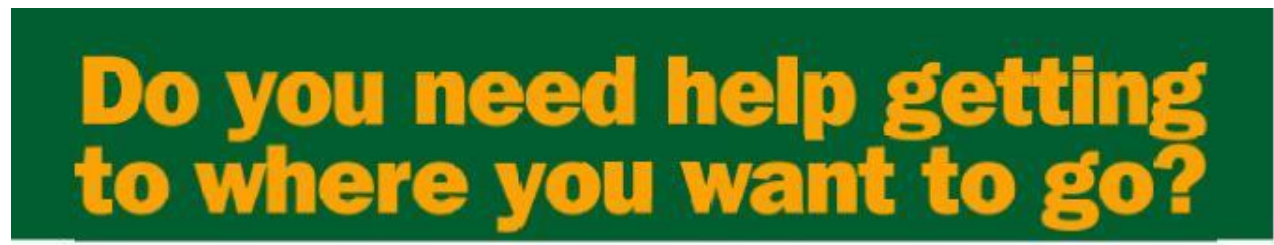

Malmesbury Area Transport Hub is an umbrella cramisation actine as a first contact point for all your transoort encuires and needs, both for individuats and ploups. Tel: 01666822143

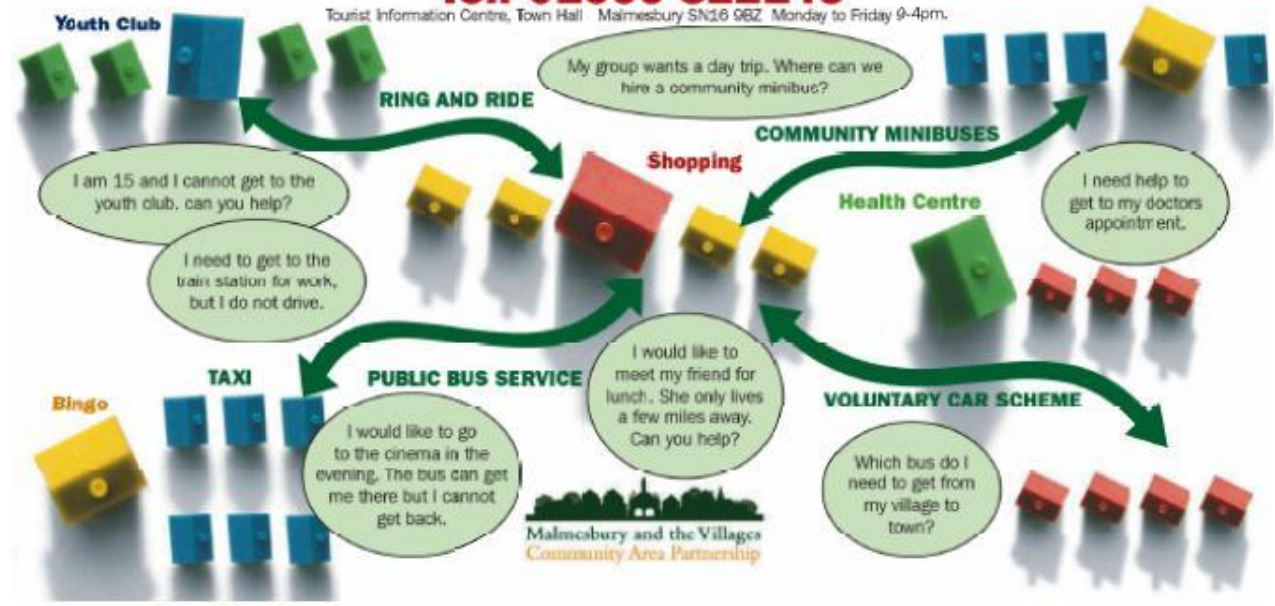

Fig. 5. Print advertisement for the Malmesbury Hub (the United Kingdom) [11].

- brochures, leaflets, flyers, bumper stickers, maps available at a bureau of the tourist information;

-PR support to establish interaction with authorities to ensure understanding and involvement (radio and TV, newspapers);

- direct mail advertising.

The implementation of different marketing and promoting activities should be coordinated with the specific stage of the marketing strategy for a transfer hub, include quantitative, qualitative and impact indicators, and target groups of consumers. In addition, promotion techniques, as a -transfer hub's popularity grows, should cover more consumers and provide a more in-depth description of the transfer hubs' possibilities and conveniences. It is necessary to coordinate advertising efforts with other programs for the benefit of all participants of the project (transport agencies, organizations providing additional services such as cafes, banks, etc.). Providing information in several languages will attract a larger audience and involve tourists.

The implementation of the transfer hubs project is not only of economic but also of great social importance and therefore the implementation of an effective marketing strategy is aimed not only at increasing the project profitability, but also at changing certain social and cultural environment and the traffic psychology of the population of the metropolis area. The effect of promotion measures should include not only economic indicators (the value of the payback period, the profitability index, the net discounted income), but also social and infrastructure improvement (traffic tension reduction, residents psychological state improvement, users of public transport number growth, etc.). 


\section{Discussion}

In this article we offer to include the development and implementation of marketing promotion strategy into the process of designing and formation of transport transfer hub according to the logic of stages of hub's evolution.

According to the concept mentioned above, transfer hub as a transport communication space needs to be incorporated network of city's public sphere. The promoting measures actions can be divided into two main groups - economic (e.g., parking fees) and psychological (creating and fostering demand). In the latter case, a continuum of activities to maintain the demand for this type of services is required. Advertising and marketing activities of a transfer hub raise the population's awareness of such state programs. The promotion of the new traffic-jams solutions will increase sustainable use of a transfer hub as well as the rate of growth of the revenue. In particular, for transfer hubs, the adaptation of the RodrigueNotteboom model [15] taking into account marketing activities for its promotion (fig. 6) is proposed.

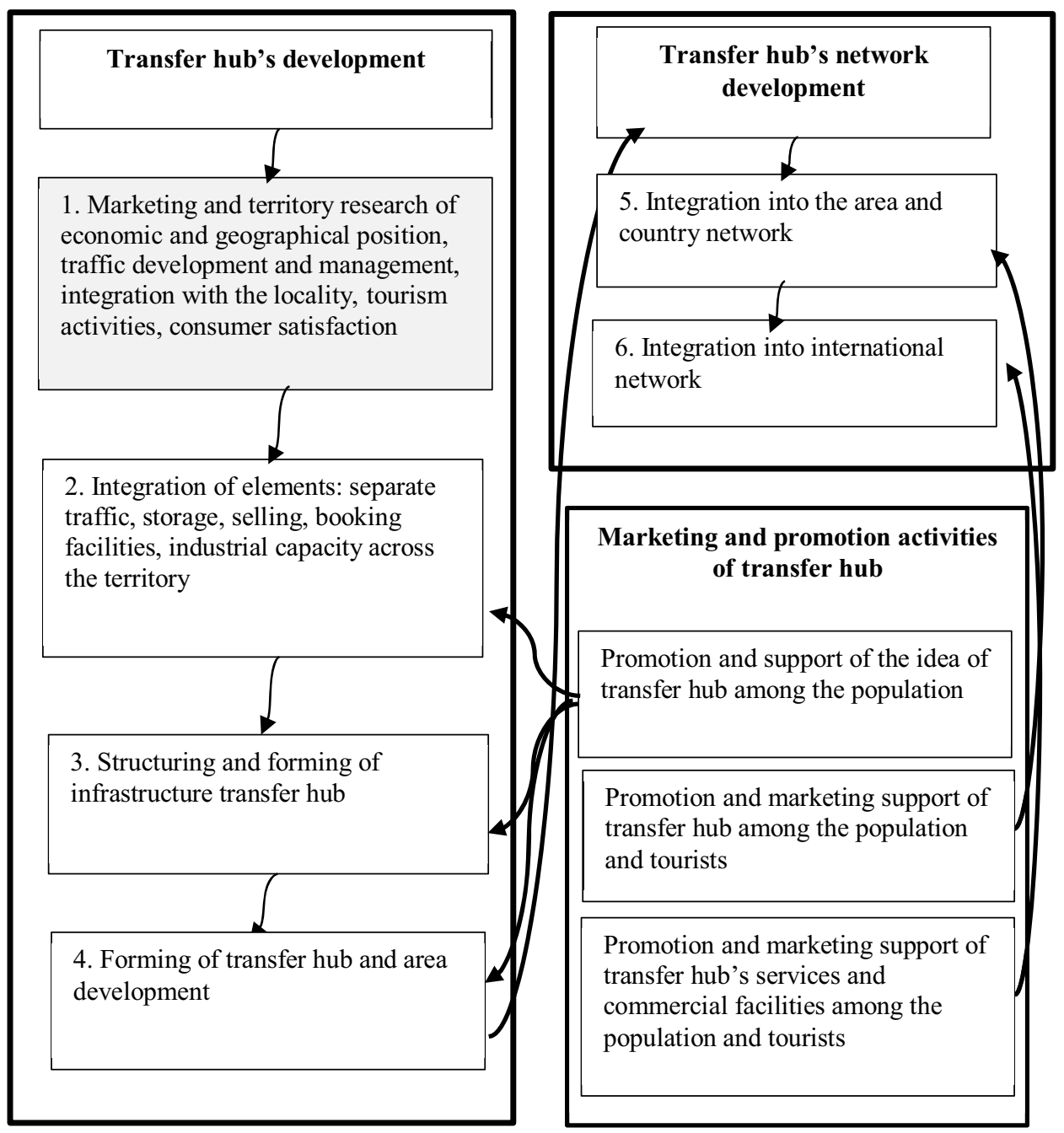

Fig. 6. The adapted model for the marketing promotion of transfer hub. 
The gradation of hub's infrastructure and its logistic forming is bound with certain marketing and promotion activities. The stages of marketing promotion strategy implementation vary from marketing and territory research of economic and geographical position, traffic development and management, integration with the locality, tourism activities, consumer satisfaction to promotion and marketing support of transfer hub's services and commercial facilities among the population and tourists.

Stage 1. Focus on research. The rationale for hub's development and its model justification (the minimalist model, the complex model and public facility model).

Stage 2. Focus on promotion and support of the idea of transfer hub among the population. Priority promotion measures to support travel and service development, the internal environment. Newspapers articles and GR and PR-materials.

Stage 3. Focus on promotion and marketing support of transfer hub among the residents and tourists. Extended promotion of transport network, services and the investment attractiveness of hub and the region as a whole, the external environment. Newspapers articles, interviews, print advertising, digital signage and web site.

Stage 4. Focus on multilingual promotion and marketing support of transfer hub's services and commercial facilities among the population and tourists. Promotion with customer focus and quality service, the virtual information support of the hub. Print advertising, web-sites, mobile applications, services commercials.

Stage 5. Revision and updating promotion and marketing support of transfer hub

The article explores marketing approach to study and promote transport hub. The adaptation of J. Rodrigue-Notteboom model takes into account the development of marketing and promotion strategy based on hierarchy of the scope of promotion. The result of the research is multilevel promotion strategy following the logic of transport hub emersion.

\section{References}

1. K. Mahmud, K. Gope, S. Chowdhury, J. of Management and Sustainability 2(2) (2012) doi:10.5539/jms.v2n2p112

2. M. Ababkova, I. Belinskaya, Izvestiya Sankt-Peterburgskogo Agrarnogo universiteta 44, 150 (2016)

3. O. Pokrovskaya, R. Fedorenko, Evolutionary-Functional Approach to Transport Hubs Classification EMMFT (2020) DOI: 10.1007/978-3-030-19756-8_33

4. D. Zheleznov, S. Leonova, Vestnik transporta Povolzh'ya 4(64), 53 (2017)

5. S. Vakulenko, N. Evreenova, Transport Hubs as the Basis of Multimodal Passenger Transportation MLSD (2019) DOI: 10.1109/MLSD.2019.8910964.

6. W. Zhanzhong, Z. Fang, J. Wei, Adaptive research of urban passenger transport hubs transfer organizational model based on coordination theory (2011) DOI: 10.1109/TMEE.2011.6199590

7. X. Cheng, Yu. Cao, K. Huang, Yu. Wang, J. of advanced transportation 4, 1 (2018) DOI: $10.1155 / 2018 / 7051789$

8. S. Unasheva, N. Korshunova, Construction, Materials and Products 3(1), 89 (2020) DOI: $10.34031 / 2618-7183-2020-3-1-89-94$

9. I. Belavincev, Nauchnyj vestnik Moskovskogo gosudarstvennogo tekhnicheskogo universiteta grazhdanskoj aviacii 202, 115 (2014)

10. E. Semenov, Metodologiya sovmeshcheniya torgovo-razvlekatel'nyh centrov $s$ transportnoperesadochnymi uzlami (Moscow, 2016)

11. I. Belinskaya, S. Shipbuildnikova, Development of investment design in the area of 
parking space organization on the example of Saint-Petersburg («Discussion», Yekaterinburg, 2015)

12. B. Schlag, J. Schade, Traffic and transportation psychology. Transport Dictionary (Edward Elgar Publishers, Cheltenham, 1997)

13. A. Bucchi, C. Sangiorgi, V. Vignali, Social and Behavioral Sciences 53, 973 (2012)

14. T. Kochetova, Social'naya psihologiya i obshchestvo 2(2), 89 (2011)

15. J. Rodrigue, C. Comtois, B. Slack, The Geography of Transport Systems (Taylor \& Francis e-Library, New York, 2006) 